\title{
Cheating in online auction - Towards explaining the popularity of English auction
}

\author{
Mamata Jenamani $^{\mathrm{a}, *}$, Yuhui Zhong ${ }^{\mathrm{b}}$, Bharat Bhargava ${ }^{\mathrm{b}}$ \\ ${ }^{a}$ Department of Industrial Engineering and Management, Indian Institute of Technology, Kharagpur, West Bengal 721 302, India \\ ${ }^{\mathrm{b}}$ Department of Computer Sciences, 250 N. University Street, West Lafayette, Indiana 47907-2066, USA
}

Received 5 August 2004; received in revised form 22 August 2005; accepted 21 December 2005

Available online 20 March 2006

\begin{abstract}
Action frauds constitute largest part of all Internet frauds. Cheating is a kind of fraud that does not have direct evidences of its occurrence. We conduct theoretical studies as well as simulation experiments to find out the effect of cheating in three important types of auctions: English auction, first-price sealed-bid, and second-price sealed-bid auction. Our cheating environment consists of shill bidding, bid shading and false bidding in English, first-price and second-price auction, respectively. In the experiments ordinary bidders, bidders with the equilibrium bidding strategy, and cheaters compete with each other. Both theoretical and experimental results confirm that the equilibrium bidding strategies indeed increases the bidders' expected utility. Therefore, it can be concluded that adoption of rational bidding strategies can combat cheating. It is found that most of the auction sites intuitively prefer English auction to other auction mechanisms. There is not much theoretical or experimental evidence to support such an intuition. We use honest bidder's expected gain and honest seller's revenue loss as a basis to compare these three important auctions types. The analysis of the results reveals English auction to be the most preferred mechanism from both honest buyer's and honest seller's point of view. This result can be used as an experimental evidence to explain the popularity of English auction over the Internet.
\end{abstract}

(c) 2006 Elsevier B.V. All rights reserved.

Keywords: Online auction; Cheating; Equilibrium bidding strategy; Buyer's expected utility; Seller's expected revenue loss

\section{Introduction}

Online auction has emerged as a popular Internet business model. It is no wonder that alongside auction frauds constitute the largest part of all Internet frauds $[1,3,4,24]$. Internet Fraud Complaint Center (IFCC) classifies auction frauds into six categories: non-delivery of goods, misrepresentation of the items, triangulation, fee staking, selling of black-market goods, multiple bidding and shill bidding [2]. The last two categories of fraud can be termed as cheating. Firstly, cheating unlike other fraud categories leaves no direct evidence of its occurrence. For example, when a shill competes with honest bidders, the bidders can only intuitively feel shill's presence with no direct evidence to validate

\footnotetext{
* Corresponding author.

E-mail addresses: mj@iem.iitkgp.ernet.in (M. Jenamani), zhong@ cs.purdue.edu (Y. Zhong), bb@cs.purdue.edu (B. Bhargava).
}

the fact. On the contrary, other types of frauds, such as nondelivery of goods, have concrete evidence. Secondly, the financial loss resulting from cheating behavior cannot be precisely measured. Consequently it is difficult to punish the cheater via law enforcement. Some of the reasons that encourage cheating over the Internet are: (1) cheap pseudonyms [14], (2) greater information asymmetry [16], (3) lack of personal contact [15], and (4) the tolerance of bidders [3].

Although there are millions of auction mechanisms, three most popular ones are: English auction (also known as open outcry auction), first-price sealed-bid auction and second-price sealed-bid auction (also known as Vickrey auction [8]). In English auction, the price of the product increases as bidders compete with each other. At the end of the auction the highest bidder can take the item after paying the price he bids.

In case of sealed-bid auction each party sends a closed enveloped bid for the item to a seller who opens all the bids 
after a predefined time period. The highest bidder gets the item. The two variations, the first-price and the secondprice sealed-bid auction are differentiated by the settlement price policy. In the former the highest bidder pays exactly the amount he bids whereas in the latter the highest bidder pays the amount of the second highest bid. In the real world most of the important auctions are sealed-bid in nature. On the contrary most Internet auctions are English auctions or its variations. According to [6], about $88 \%$ Internet auctions are English auction and its variants. Other forms of auctions, such as Vickrey auction and double auction, account for the rest $11 \%$.

In this paper we present the equilibrium bidding strategies of a rational agent in the above three types of auction mechanisms in cheating environments from game theoretic models. Our cheating environments consist of shill bidding, bid shading and false bidding in English, first-price and second-price auction, respectively. We theoretically evaluate the bidder's expected utility and the seller's expected revenue loss under different probability of cheating for three different distributions of reservation values (defined later) - uniform distribution, exponential distribution and some arbitrary polynomial distribution. We find the efficiency of these strategies through the simulation experiments and relate this with the theoretical result. We also compare the bidders' expected utility and seller's expected revenue loss in three types of auction mechanism. The analysis of the results shows English auction performing better from both bidders and sellers point of view.

The rest of the paper is organized as follows. First we discuss on various types of cheatings in electronic auctions. In particular we discuss the types of cheating possible in three important auction mechanisms. Next the equilibrium bidding strategies for the auctions are introduced. In the subsequent sections we present the theoretical findings followed by the results of a simulation experiment and relate them. Before concluding the paper, we present a survey of the related works.

\section{Cheating in electronic auction}

In auctions, sellers try to sell the item in a price as much as possible to increase their expected revenue. The interest of a buyer is just the opposite; they want to buy the item in a price as low as possible. Cheating occurs if they adopt unfair practices to achieve these goals. Cheating may be induced either by a bidder (buyer) or an auctioneer (seller) as shown in Fig. 1.

Multiple bidding. A bidder can place multiple bids on the same item using different aliases [14].

Bid shading. Some mechanisms, such as first- and second-price sealed-bid auctions, do not reveal the bids before auction clears. Under such circumstance, a bidder's best strategy is to bid according to his valuation of the item. A bidder may adopt some unfair ways to examine the bids and revise his bid to win the auction at a minimum price far below his valuation. This practice is called bid shading $[7,9]$.

Rings. A group of bidders form a coalition called the ring. These ring members collude not to compete with each other and do not raise the price of the object [13].

Shill bidding. A corrupt seller appoints fake bidders (shills) who place bids to increase the price of the item without any intention of buying it $[16,17]$.

False bids. A seller cheats in a second-price sealed-bid auction by looking at the bids before the auction clears and submitting an extra bid just below the price of the highest bid. Such extra bids are often called false bids [7].

Type of cheating is auction mechanism specific. We now present the types of cheating possible in the three important of auction mechanisms under consideration.

\subsection{Cheating in second-price sealed-bid auction}

Theoretically second-price sealed-bid auctions have many advantages over other types of auction mechanisms [8]. This mechanism is not widely adopted due to the fear of a cheating seller [9]. In this auction, a winner who offers the highest bid gets the item with the second highest price. However, if a dishonest seller secretly opens the bids before the auction clears, he can submit a false bid whose value is a little less than the highest offer [7]. The winner has to pay the phony second highest price, which decreases his expected gain. For example if the highest bid is $\$ 1000$ and the second highest bid is $\$ 800$, then a cheating seller can introduce a false bid of value $\$ 999$. So the winner has to pay $\$ 999$

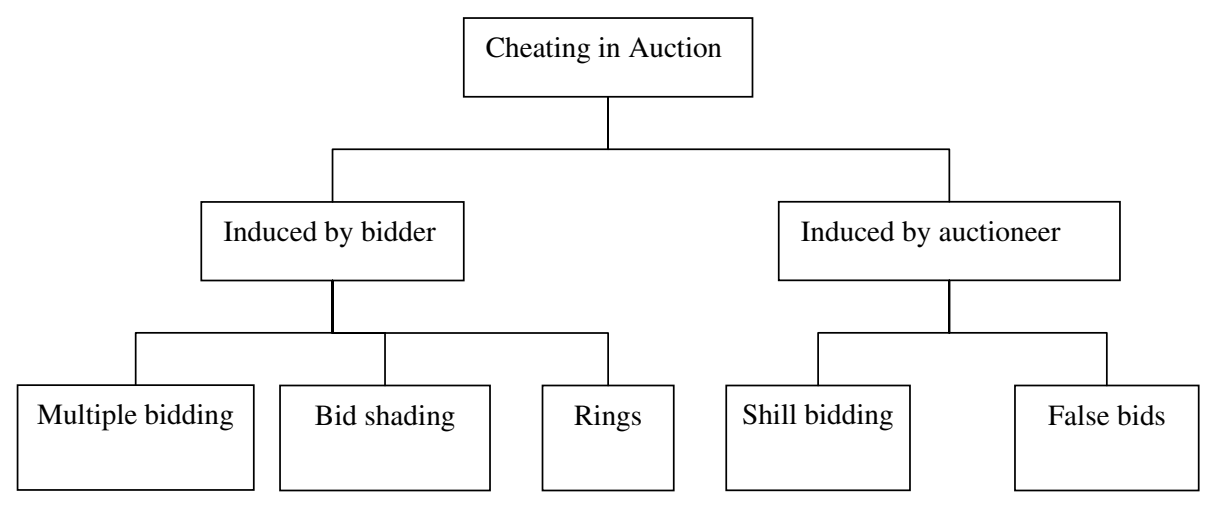

Fig. 1. Cheating in electronic auction. 
(Almost same as his bid) instead of $\$ 800$, and thus decreasing the expected gain of the winner. Rothkopf and Harstad [12] have shown that if the cheating of a seller is found the buyers start shading their bids and in the long run the second-price auction becomes less profitable than any other auction.

\subsection{Cheating in first-price sealed-bid auction}

In first-price sealed-bid auction the highest bidder gets the item with his declared bid value. So the seller does not have a scope to cheat. A bidder can however adopt unfair ways violating the auction principle to examine other bidder's bids and shade his bids. He can go on revising his bids with multiple identities.

\subsection{Cheating in English auction}

Cheating in English auction can take place either in the form of shill bidding or multiple bidding [16,17]. An seller cheats by appointing shills. A bidder cheats by adopting multiple bidding practices.

A shill tries to escalate the price without any intention of buying the item. Occasionally the shill wins the auction if no other higher bid comes before auction ends. The item to be sold remains with the seller. Such items are re-auctioned at a latter time. If the item is auctioned in a site that does not charge any transaction fee then the seller neither loses nor gains in the process of shill bidding. If there is some entry fee then the seller has to bear the loss. Most auction sites in practice charge a listing fee for all the auctioned items. In addition, the site may also charge a commission fee on the winning auctions. If these fees are low, they cannot deter shill bidding. However, increasing fees may result in loosing sellers to other sites. Cheatings conducted by sellers in English auction and second-price auction are different. In case of second-price auction the seller manages to increase his profit up to the declared highest bid price. The goal of the cheating in English auction is to induce the bidders to reach their maximum valuations.

In case of multiple bidding a cheating agent submits many bids adopting multiple (fake) identities. Some of these bids are higher than his personal valuation of the product. The fake bidders drive their bids to such an extent that other participants prefer to withdraw. Towards the end of the auction the cheater also withdraws all his bids except the one, which is just above the second highest bid and acquires the product in the lowest possible price. This kind of cheating is possible in the sites that allow bid withdrawal.

Several approaches have been proposed to detect and deter cheatings in online auction [17]. These counter measures are to be enforced by auction sites and the bidders and the sellers are to abide by these rules. In this approach the auction site's intermediation is necessary to deter fraud. We propose that if a bidder adopts an equilibrium bidding strategy then he can reduce the effect of cheating without the intermediation of the auction site. The following section elaborates the idea.

\section{A model to understand the impact of cheating auctions}

Consider auction for a single indivisible item. Each bidder associates two values with the item - a reservation value and a bid. Reservation value is the maximum price a bidder is willing to pay for the item based on his personal valuation. This information is private to each bidder. A bid on the other hand is the publicly declared price that a bidder is willing to pay. In order to understand the impact of cheating and to compare the cheating auctions we consider only one type of cheating that is prevalent in each auction mechanism. We consider shill bidding, bid shading and false bidding in English, first-price and second-price auctions, respectively.

$N$ bidders and a seller participate in the auction. Each bidder has a reservation value $\theta_{i}(i=1,2, \ldots N)$ for the item. Without loss of generality we assume $\theta_{i} \in[0,1]$. Each agent's reservation value is independently drawn from a cumulative distribution function (CDF) $F$ over $[0,1]$, where $F(0)=0$ and $F(1)=1$. We assume $F($.$) is strictly increasing and differen-$ tiable in the interval $[0,1]$. The derivative of $\operatorname{CDF}, f(\theta)$ is then the probability density function (PDF). Each bidder knows his reservation value and the distribution $F$ of other agents. A bidding strategy $b_{i}:[0,1] \rightarrow[0,1]$ maps a bidder's reservation value to its bid. As we mention earlier $\theta=\left(\theta_{1}\right.$, $\left.\theta_{2}, \ldots, \theta_{n}\right)$ is the vector of reservation values of all the agents and $b(\theta)=\left(b_{1}\left(\theta_{1}\right), b_{2}\left(\theta_{2}\right), \ldots, b_{n}\left(\theta_{n}\right)\right)$ is the vector of bids.

\subsection{Bidder's expected gain (utility)}

The expected utility (gain) of a winner is the difference between his reservation value and his expected payment.

The expected gain of a buyer is defined by Riley and Samuelson [10] as follows:

Expected bidder's gain $=$ Probability of winning

$$
\begin{aligned}
& \times(\text { Reservation value }-\mathrm{Bid}) \\
= & \text { Probability of winning } \\
& \times\left(\theta_{i}-b_{i}\left(\theta_{i}\right)\right)
\end{aligned}
$$

It is assumed that the bidders are rational and risk neutral. A bidder is indifferent between loosing the auction and winning it in his reservation value. He quits the auction if the price goes beyond his reservation value and try to maximize his utility. The equilibrium bidding strategy of an honest agent in cheating auction can be found by taking the derivative of the equation with respect to $b_{i}\left(\theta_{i}\right)$, and setting it to zero.

\subsection{Probability of winning in cheating auctions}

In order to calculate a buyer's expected gain (Eq. (1)), we find the probability of winning for each type of auction in this section. 
In English auction an honest bidder wins the auction if his bid value is greater than that of the bid value of the shill and the reservation value of other honest bidders. Let the seller have a reservation value $\theta_{\mathrm{s}}$, which is a constant for a specific auction. The shill's bid is greater than that of the seller's reservation value. It is also less than that of the reservation value of the winner (an honest bidder). The probability that an honest bidder $i$ beats a shill $j$ is then $\operatorname{Prob}\left(\theta_{\mathrm{s}} \leqslant b_{j}\left(\theta_{j}\right) \leqslant \theta_{i}\right)=F\left(\theta_{i}\right)-F\left(\theta_{\mathrm{s}}\right)$. It is not profitable for a seller to accept any bid below his reservation value [10]. So we can assume $F\left(\theta_{s}\right)=0$. The probability that bidder $i$ has a higher bid than a cheater can be represented by $F\left(\theta_{i}\right)$. The probability that bidder $i$ beats any other honest bidder is $F\left(b_{i}\left(\theta_{i}\right)\right)$ because each honest bidder's reservation value has to be less than that of the bid value of the winner.

The probability that an honest bidder's bid is higher than that of any other bidder is the weighted average of these two probabilities, the weights being the probability of cheating $\left(P^{b}\right)$ and non-cheating $\left(1-P^{b}\right)$, respectively. We raise this probability to the power $N-1$ to get the probability of winning the auction because the winner's bid is higher than other $N-1$ bidders:

$\left[P^{b} . F\left(\theta_{i}\right)+\left(1-P^{b}\right) \cdot F\left(b_{i}\left(\theta_{i}\right)\right)\right]^{N-1}$

In second-price sealed-bid auction an honest bidder $i$ wins if his bid is greater than the bids of the other bidders including the false bid of the seller [7]. Equivalently, the reservation value $\theta_{j}$ of any other agent $j$ is below than that of the reservation value $\theta_{i}$ of the winner. Formally, $\operatorname{Prob}\left(\theta_{j} \leqslant \theta_{i}\right)=F\left(\theta_{i}\right)$. So the probability that it is higher than that of the all $N-1$ bidders is this probability raised to $(N-1)$ th power. So the probability of cheating in second-price sealed-bid auction is:

$F^{N-1}\left(\theta_{i}\right)$

In first-price sealed-bid auction an honest bidder $i$ wins the auction if and only if his bid exceeds every other honest bidder's bid and every cheater's reservation value [7]. The probability that the winner's bid $b_{i}\left(\theta_{i}\right)$ is greater than that of another honest bidder $j$ s bid $b_{j}\left(\theta_{j}\right)$ is $\operatorname{Prob}\left(b_{j}\left(\theta_{j}\right) \leqslant b_{i}\left(\theta_{i}\right)\right)=\operatorname{Prob}\left(\theta_{j} \leqslant \theta_{i}\right)=F\left(\theta_{i}\right)$. The probability that the winner's bid $b_{i}\left(\theta_{i}\right)$ is greater than that of a cheater $j$ 's reservation value $\theta_{j}$ is $\operatorname{Prob}\left(\theta_{j} \leqslant b_{i}\left(\theta_{i}\right)\right)=F\left(b_{i}\left(\theta_{i}\right)\right)$. Let us assume that each bidder cheat with the probability $P^{a}$. So the probability that the winner beats any other bidder is the weighted average of these two probabilities. Now the probability that the winner beats every other bidder is this probability raised to the power $(N-1)$. So the probability of cheating in first-price sealed-bid auction is:

$\left[P^{a} \cdot F\left(b_{i}\left(\theta_{i}\right)\right)+\left(1-P^{a}\right) \cdot F\left(\theta_{i}\right)\right]^{N-1}$

\subsection{The equilibrium bidding strategy}

In this section we present the equilibrium bidding strategy in three types of auctions. The detailed derivations of these are available elsewhere. Therefore we just refer the equations for our work. The interested readers may refer the original work for more detail. Following our work in [5] we consider: an English auction in which each bidder cheats with the probability $P^{b}$, it is a Bayes Nash equilibrium for each non-cheating bidder $i$ to bid according to the strategy that is a fixed point in the following equation:

$b_{i}\left(\theta_{i}\right)=\theta_{i}-\frac{\int_{0}^{\theta_{i}}\left(P^{b} \cdot F(x)+\left(1-P^{b}\right) \cdot F\left(b_{i}(x)\right)\right)^{N-1} \mathrm{~d} x}{\left(P^{b} \cdot F\left(\theta_{i}\right) \cdot+\left(1-P^{b}\right) \cdot F\left(b_{i}\left(\theta_{i}\right)\right)\right)^{N-1}}$

Following the work of Porter and Shoham [7] we consider: In a second-price sealed-bid auction in which the seller cheats with the probability $P^{c}$, it is a Bayes Nash equilibrium for each non-cheating bidder $i$ to bid according to the following strategy:

$b_{i}\left(\theta_{i}\right)=\theta_{i}-\frac{\int_{0}^{\theta_{i}} \cdot F^{\frac{N-1}{p^{c}}}(x) \mathrm{d} x}{F^{N-1} p^{c}}\left(\theta_{i}\right)$.

In a first-price sealed-bid auction in which each bidder cheats with the probability $P^{a}$, it is a Bayes Nash equilibrium for each non-cheating bidder $i$ to bid according to the strategy that is a fixed point in the following equation:

$b_{i}\left(\theta_{i}\right)=\theta_{i}-\frac{\int_{0}^{\theta_{i}}\left(P^{a} \cdot F\left(b_{i}(x)\right)+\left(1-P^{a}\right) \cdot F(x)\right)^{N-1} \mathrm{~d} x}{\left(P^{a} \cdot F\left(b_{i}\left(\theta_{i}\right)\right) \cdot+\left(1-P^{a}\right) \cdot F\left(\theta_{i}\right)\right)^{N-1}}$

\section{A framework for understanding the impact of cheating auctions}

Cheating brings short-term benefits to the cheater. The ease of adopting fake and multiple identities boosts the cheaters' confidence. It is also difficult to prevent cheating in Internet auctions. Law enforcement is also difficult over the Internet. Therefore, it is worth evaluating which type of auction is better in potential cheating environment. "Better-ness" is measured from honest participants (bidder or seller) points of views. For a bidder, a good mechanism leads to large expected gain in the presence of cheaters. For a seller, the goodness is expressed in terms of expected revenue loss.

\subsection{From honest bidder's perspective}

Suppose an honest bidder has the option to choose from three type of auction in potential cheating environments. It is desirable that he has fair idea about his expected gains in each case. We consider the definition of expected gain of a buyer by Riley and Samuelson [10] presented in Eq. (1). The probability of cheating in each type of auction is given in Eqs. (2)-(4), respectively. The equilibrium bidding strategies for an honest bidder are given in Eqs. (5)-(7), respectively.

Some authors consider the expected gain of the winner as the expected revenue loss for the seller [7]. As specified earlier the expected gain is the difference between the winner's reservation value and the final bid. Thus, if we assume the expected revenue loss as defined by [7], in turn we 
assume that when there is no cheating the bidder would place the final bid equal to that of his reservation value which is not realistic. So in the following paragraph we present a different approach for evaluating the expected revenue loss of a seller.

\subsection{From honest seller's perspective}

We define expected revenue loss to be the difference between the maximum possible expected revenue in the non-cheating environment and expected revenue in cheating environment. The expected revenue for a seller is defined by Riley and Samuelson [10] to be $N$ times the expectations on the expected payment of a typical buyer. Assuming that the seller knows the distribution $F\left(\theta_{i}\right)$ of the reservation values, his expected revenue is:

$R=N \int_{0}^{\theta_{i}} P(\theta) F^{\prime}(\theta) \mathrm{d} \theta$

where $P(\theta)$ is the expected payment by a single buyer and $P\left(\theta_{i}\right)=\operatorname{Prob}\left\{b\left(\theta_{i}\right)\right.$ is high bid $\} \times b\left(\theta_{i}\right)$. The expected revenue in case of three types of cheating auctions can be evaluated using this formulation.

We use the fact that the optimal auctions maximize a seller's expected revenue [11]. According to revenue equivalence theorem the expected revenues from all the optimal auctions are same. The expected revenue in a non-cheating environment for any optimal auction can be computed using the following formula [10]:

$R=N \int_{0}^{\theta_{i}}\left[\theta F^{\prime}(\theta)+F(\theta)\right] F^{N-1}(\theta) \mathrm{d} \theta$

\subsection{Results}

In this section we present the theoretical results of comparison of three types of cheating auction. We consider three distributions: uniform distribution $\left(F\left(\theta_{i}\right)=\theta_{i}\right)$, normalized exponential distribution $\left(F\left(\theta_{i}\right)=\frac{e^{\theta_{i}}-1}{e-1}\right)$ and an arbitrary polynomial distribution $\left(F\left(\theta_{i}\right)=-\frac{1}{2} \theta_{i}^{2}+\frac{3}{2} \theta_{i}\right)$. Table 1 shows expectation of buyer's expected utility and seller's expected revenue loss over all the $\theta_{i}$ (reservation values) in three auction types. We consider the cases while probability of cheating is 0.2 (low), 0.5 (moderate) and 0.9 (high).

From honest bidder's perspective it is observed that:

1. Irrespective of the distribution of the reservation price and the number of bidders participating in the auction process, buyer's expected utility in second-price and English auction increases with the increase in the probability of cheating. However, it decreases in first-price

Table 1

Expectations on buyer's expected utility and seller's expected revenue loss

\begin{tabular}{|c|c|c|c|c|c|c|c|}
\hline \multirow[t]{2}{*}{ Distribution } & \multirow[t]{2}{*}{ Probability of cheating } & \multicolumn{3}{|c|}{ Buyer's expected utility } & \multicolumn{3}{|c|}{ Seller's expected revenue loss } \\
\hline & & $N=2$ & $N=10$ & $N=25$ & $N=2$ & $N=10$ & $N=25$ \\
\hline \multicolumn{8}{|l|}{ Uniform } \\
\hline \multirow[t]{3}{*}{ Second-price sealed-bid auction } & 0.2 & 0.0564 & 0.0021 & & -0.1401 & -0.0137 & -0.0026 \\
\hline & 0.5 & 0.1125 & 0.0049 & & -0.1120 & -0.0113 & -0.0021 \\
\hline & 0.9 & 0.1598 & 0.0084 & 0.0014 & -0.0883 & -0.0083 & -0.0016 \\
\hline \multirow[t]{3}{*}{ First-price sealed-bid auction } & 0.2 & 0.1656 & 0.0105 & 0.0020 & -0.0689 & 0.0110 & 0.0092 \\
\hline & 0.5 & 0.1335 & 0.0068 & 0.0012 & -0.0572 & 0.0274 & 0.0187 \\
\hline & 0.9 & 0.0933 & 0.0038 & & -0.0422 & 0.0414 & 0.0259 \\
\hline \multirow[t]{3}{*}{ English auction } & 0.2 & 0.1030 & 0.0044 & & -0.0459 & 0.0385 & 0.0245 \\
\hline & 0.5 & 0.1335 & 0.0068 & 0.0012 & -0.0572 & 0.0274 & 0.0187 \\
\hline & 0.9 & 0.1765 & 0.0121 & 0.0023 & -0.0728 & 0.0039 & 0.0048 \\
\hline \multicolumn{8}{|l|}{ Exponential } \\
\hline \multirow[t]{3}{*}{ Second-price sealed-bid auction } & 0.2 & 0.0375 & & & -0.1269 & -0.0071 & -0.0012 \\
\hline & 0.5 & 0.0806 & 0.0023 & & -0.1045 & -0.0059 & \\
\hline & 0.9 & 0.1207 & 0.0040 & & -0.0839 & -0.0044 & \\
\hline \multirow[t]{3}{*}{ First-price sealed-bid auction } & 0.2 & 0.1420 & 0.0065 & 0.0011 & -0.0566 & 0.0152 & 0.0096 \\
\hline & 0.5 & 0.1092 & 0.0034 & & -0.0447 & 0.0292 & 0.0170 \\
\hline & 0.9 & 0.0683 & 0.0014 & & -0.0293 & 0.0391 & 0.0212 \\
\hline \multirow[t]{3}{*}{ English auction } & 0.2 & 0.0782 & 0.0018 & & -0.0331 & 0.0373 & 0.0205 \\
\hline & 0.5 & 0.1092 & 0.0034 & & -0.0447 & 0.0292 & 0.0170 \\
\hline & 0.9 & 0.1531 & 0.0080 & 0.0014 & -0.0606 & 0.0084 & 0.0056 \\
\hline \multicolumn{8}{|l|}{ Polynomial } \\
\hline \multirow[t]{3}{*}{ Second-price sealed-bid auction } & 0.2 & 0.0817 & 0.0052 & 0.0010 & -0.1398 & -0.0253 & -0.0066 \\
\hline & 0.5 & 0.1492 & 0.0117 & 0.0025 & -0.1073 & -0.0203 & -0.0054 \\
\hline & 0.9 & 0.2013 & 0.0191 & 0.0042 & -0.0815 & -0.0146 & -0.0039 \\
\hline \multirow[t]{3}{*}{ First-price sealed-bid auction } & 0.2 & 0.1893 & 0.0174 & 0.0038 & -0.0692 & 0.0022 & 0.0066 \\
\hline & 0.5 & 0.1585 & 0.0132 & 0.0029 & -0.0577 & 0.0207 & 0.0183 \\
\hline & 0.9 & 0.1200 & 0.0093 & 0.0020 & -0.0430 & 0.0389 & 0.0293 \\
\hline \multirow[t]{3}{*}{ English auction } & 0.2 & 0.1293 & 0.0101 & 0.0021 & -0.0466 & 0.0349 & 0.0269 \\
\hline & 0.5 & 0.1585 & 0.0132 & 0.0029 & -0.0577 & 0.0207 & 0.0183 \\
\hline & 0.9 & 0.1998 & 0.0191 & 0.0042 & -0.0731 & -0.0052 & 0.0018 \\
\hline
\end{tabular}


auction. This fact explains the bidders are more cautious towards sellers cheating in English and second-price auction than the cheating by the fellow bidders in firstprice auction.

2. Irrespective of auction mechanism, probability of cheating and the distribution of reservation price the utility decreases when the number of bidders increase in the system in all three auction types. This indicates as the competition gets more intense the bidders shade their bids less and less.

From honest seller's perspective it is observed that:

3 . The expected revenue loss in case of second-price auction is always negative. This means that the expect revenue of an honest seller in a cheating environment is never less than that of a non-cheating optimal auction if second-price auction is adopted. When the numbers of buyers increase in the system they shade their bids less and the revenue loss tends to be zero. A seller can cheat in a second-price auction by introducing a fake bid. If he chooses to do so then he can increase his revenue.

4. Revenue loss is negative in all auction types when numbers of bidders are less in the system. Therefore, we can say that the effect of cheating is worst when numbers of bidders are less in the system. Observation 2 also supports this fact.

Table 1 show that above four observations is invariant of the underlying distribution of the reservation values. Therefore, our simulation experiment considers uniform distribution only.

\section{A simulation experiments to understand the impact of cheating}

Three separate experiments for each auction type are conducted. $N$ bidders participate in the auction processes. Each member of the bidder population draws its reservation value from the uniform distribution. The reservation value is private to the corresponding bidder. Each bidder is randomly assigned one of the two bidding strategies equilibrium bidding strategy or ordinary strategy. In ordinary strategy the bidder bids up to his reservation price where as in equilibrium strategy the maximum bid value of a bidder is determined using Eqs. (5)-(7) for the three auction mechanisms, respectively. Each auction continues for a duration $T$. This can be discretized into $T$ periods of equal length. Time $t$ between the arrivals of bids is represented by an exponential distribution with mean $(1 / \lambda)$ and cumulative distribution function $1-\mathrm{e}^{-\lambda t}$ where the arrival rate of the bids is $\lambda$. Buyer's expected utility and the sellers expected revenue loss is the expectation over 1000 run of each experiment.

In English auction out of the $N$ bidders participating in the auction process; one of the bidders is a shill. Without loss of generality we assume the $N$ th bidder is the shill. Since a shill is appointed by the seller we assume the valu- ation of the product by both the seller and the shill are the same. Therefore, the reservation value of the shill is used as the reserve price of the seller. This value is declared as the initial listing price of the item. A bidder is randomly selected from the population after $t$ time units and submits a bid following the corresponding bidding strategy. All bidders except the shill bid less than or equal to their reservation values. A shill is activated after a fixed interval and tries to escalate the price. The system minimizes the probability of shill winning the auction by stopping it few intervals before the auction ends. In spite of this, if shill wins she is allowed to withdraw her bid.

In first-price auction cheating is initiated by the bidders. Some of the bidders act as the cheaters (bid shaders). The cheaters (by some illicit means) have the knowledge of all the bids submitted before them violating the rule of the sealed-bid auction. They bid multiple times with a minimum increment on the highest bid. In second-price auction the cheating seller submits a fake bid just before the auction closes. A fake bid is a minimum increment lower than the highest bid.

\subsection{Results}

Fig. 2(a)-(c) shows the bidder's expected utility for different bidding strategies for English, first-price sealed-bid and second-price sealed-bid auctions, respectively, when the probability of cheating is high (0.9). In English auction, the ordinary bidder bids up to his reservation value. Therefore, he can get exploited by the shill and his expected utility (Fig. 2(a)) becomes zero. The bidders adopting shill counteracting (equilibrium) bidding strategy has a positive utility. In first-price auction the cheating bidders (bid shaders (BS)) modify their bids many times by illegally knowing others' bids. Naturally they have highest expected utility (BS, Fig. 2(b)).

Out of the honest bidders - ordinary bidders end up getting zero expected utility where as bidders with bid shading counteracting (equilibrium) bidding strategy (BSC) get a positive utility. Fig. 2(c) shows the expected utility values for ordinary and false bid counteracting (equilibrium) bidding strategy (FBC). The expected utility of an ordinary bidder is not zero in this case because he has to pay the second highest price - the false bid, which is a minimum amount less than the highest price. The equilibrium bidding strategy derived theoretically is also found to be the best bidding strategy through these experiments.

Following observations can be made from the comparative plots for bidder's expected gain and seller's expected revenue loss for different probability of cheating shown in Fig. 3.

- Plots (a), (c) and (e) confirm the prime of English auction in the cheating environment from bidder's point of view. This result is stronger in the experiment compared to the theoretical observations. Therefore, we 

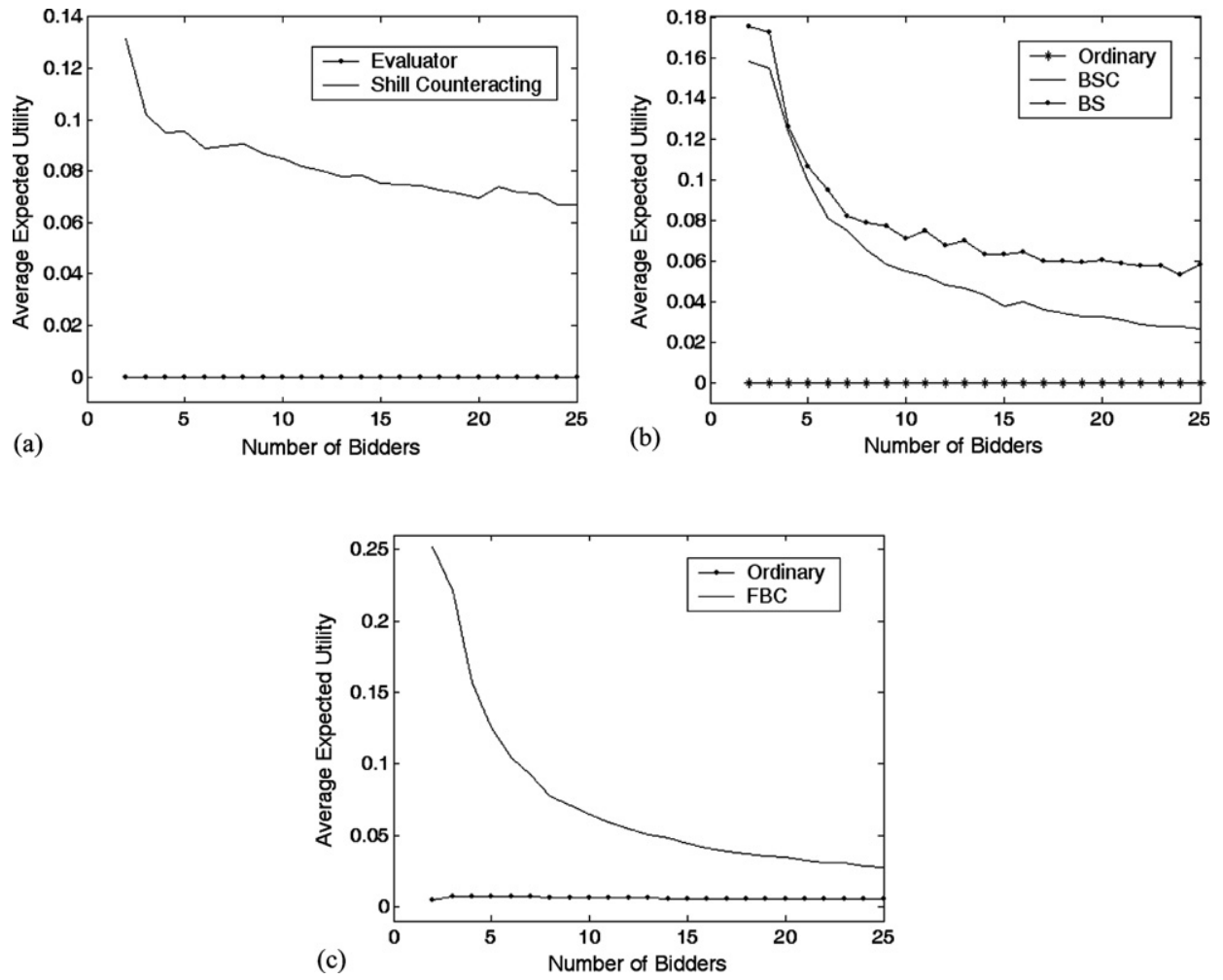

Fig. 2. Bidders' expected utility in three important auction types (a) English auction. (b) First-price sealed-bid auction. (c) Second-price sealed-bid auction.

may argue that in reality English auction is likely to be better than the other two types of auctions from bidders' point of view.

- Confirming the theoretical findings the expected revenue loss found experimentally in case of second-price auction is never positive (Fig. 3b, $\mathrm{d}$ and $\mathrm{f}$ ). This means that the expect revenue of an honest seller in a cheating environment is never less than that of the non-cheating optimal auction if second-price auction is adopted. When the numbers of buyers increase in the system they shade their bids less and the revenue loss tends to be zero.

- Surprisingly the second-price auction in spite of its rarity is found to be most preferable type of auction from seller's point of view. We refer to the work of Rothkopf and Harstad [12] to explain this rather strange result. They have shown using a dynamic model that if a seller adopts cheating in second-price auction his revenue will continue to decrease over the time and reach a stage where it will be less profitable than a first-price auction. Since our model is static in nature, we can assume that that as the time passes the second-price auction will be no more profitable for the seller.

- Though the revenue loss in English auction is more compared to second-price auction, it performs better than the first-price auction. Based on the above observations and particularly the assumption of decreasing profit in second-price auction in the last observation, English auction emerges as the most preferable mechanism for both honest buyers and the honest seller. It provides the highest expected gain for the winning buyer and very little revenue loss for the seller in the cheating environment. This result can be used to explain the popularity of English auction over the Internet where there is fear of cheating.

\section{Related work}

Lately, the popularity of online auctions have drawn the attention of computer and information scientists [18-20]. Their work is supported by the volume of the literature available from economists and management scientists. The study of bidder's behavior is an interesting field of research in the auction literature. Riley and Samuelson [10] present a framework for generating equilibrium bidding strategy for a large class of auctions. They also provide a methodology for comparing all types of auctions in terms of bidder's and seller's gains. A comprehensive review of the auction literature can be found in [11].

Literature admits cheating is a common phenomenon in the auction process. Graham and Marshal [13] model the collusive bidder behavior in second-price and English auction. In this type of cheating the bidders form a coalition called ring. Ring members never compete seriously against each other. When one of the ring members wins, the gain is divided equally among ring members. The authors extend 


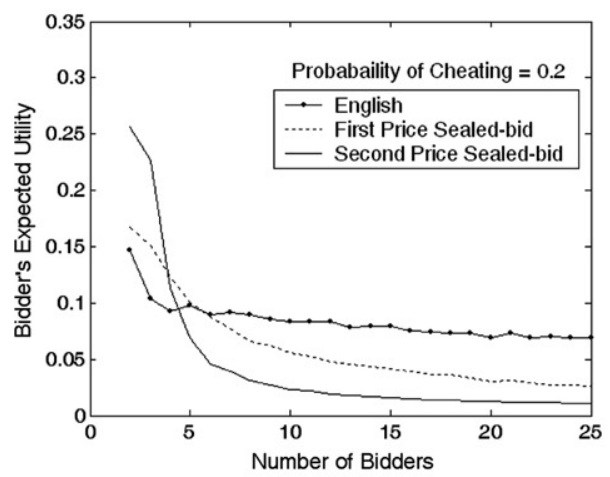

(a)

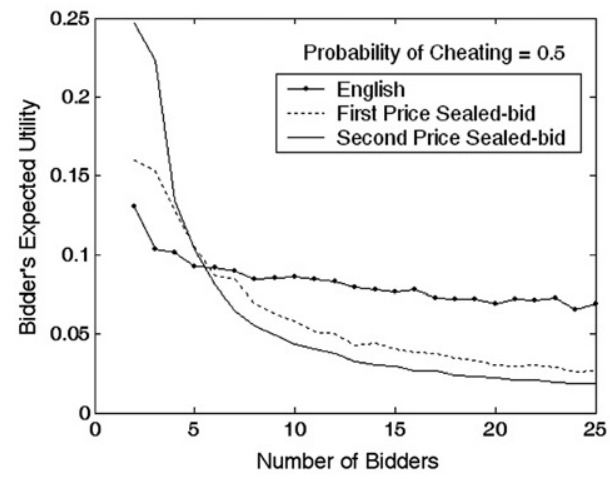

(c)

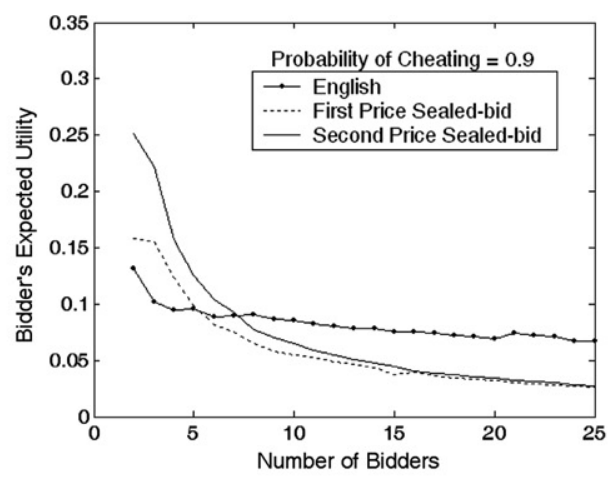

(e)

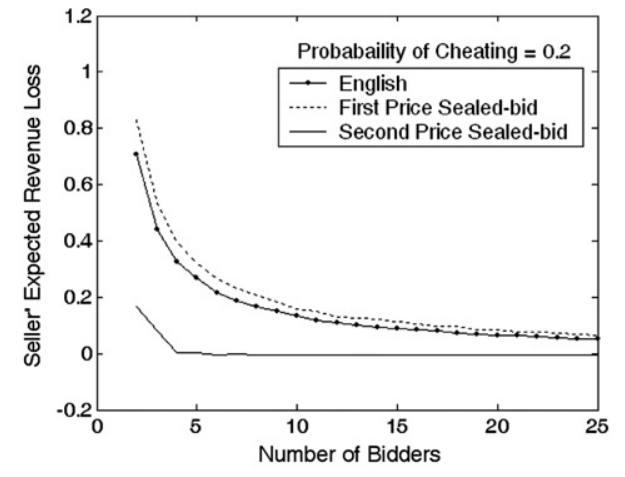

(b)

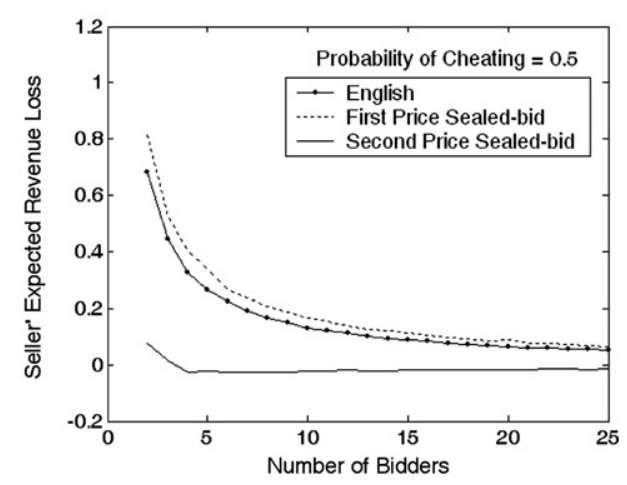

(d)

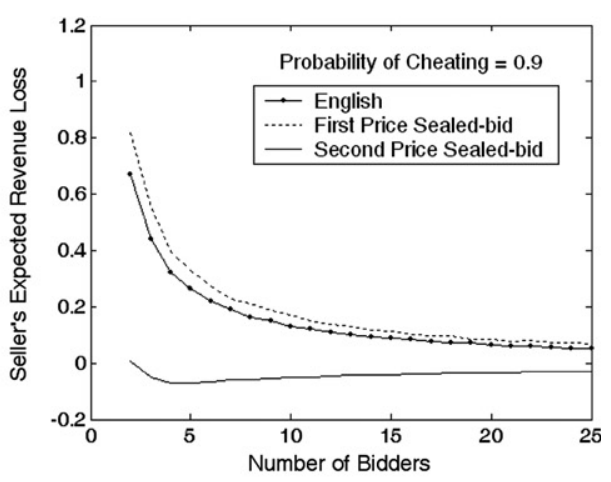

(f)

Fig. 3. Bidders' expected utility and seller's expected revenue loss in three important auction types with different probability of cheating.

the revenue equivalence of the second-price and English auction to accommodate such cooperative behavior. They conclude that both the seller's reserve price and the expected payoff to a ring member is an increasing function of the size of the coalition.

Rothkopf and Harstad [12] present two models - a static game-theoretic model and a dynamic bid-taker reputation model, to exhibit that Vickrey auctions will be driven out by first-price sealed-bid auctions when there exists possibility of cheating. They consider in Vickrey auctions, a seller may introduce a fictitious bid just below the highest submitted bid after observing the submitted bids such that the payment of the winner will be increased. Their game-theoretic model shows if cheating exists, only the most dishonest type prefers Vickrey auction to first-price auctions. The dynamic reputation model indicates that in the setting of repeated Vickrey auction, a dishonest bid-taker has no reason to conduct this kind of auction because he will be caught eventually and loose his reputation afterwards.

In a combinatorial auction, multiple goods are sold simultaneously. Bidders bid on any combination of goods. A dishonest bidder may submit false bids under fake identities, which is called false-name-bid. A protocol is falsename-proof if truth-telling without using false-name bids is a dominant strategy for bidders. Yokoo et al. [14] prove that Vickrey-Clarke-Groves (VCG) mechanism is not false-name-proof. They conclude that when surplus func- 
tion is concave over bidders the VCG mechanism is falsename-proof.

Chua and Wareham [24] present a study on types of online auction frauds, existing mechanisms to combat them. Porter and Shoham [7] derive the equilibrium bidding strategies for an honest bidder who is aware of cheating in online sealed-bid auctions. They consider two forms of cheating. In case of second-price auction a seller inserts a fake bid to increase the payment of the winner. In case of first-price auction a bidder examines the competing bids and submits a bid to win the auction with minimum payment. They also find the expected revenue loss for an honest seller due to cheating is more in first-price auction than in the second-price auction.

Auction sites like eBay use reputation mechanism that can be used to encourage honest behavior. Kauffman and Wood [16] distinguish between two different types of shilling that exhibit different motivation and behavior: shilling can be used to make the bidders pay more for an item (i.e., competitive shilling) and shilling that can be used to avoid paying auction house fees (i.e., reserve price shilling). Their results show that with reserve price shilling, bidders tend to repeat their behavior, book value and starting bids are indicative of reserve price shilling.

Wang et al. [17] shows private-value English auctions with shill bidding can result in a higher expected seller profit than other auction formats, violating the classical revenue equivalence theory. Roth and Ockenfels [18] observe substantial late bidding in both eBay and Amazon's site. They propose late bidding may be a strategy to avoid incremental price war especially from the shill bidders. This strategy however carries the risk of a bid not being transmitted successfully at the last minute (due to network delay) which may cause lower expected revenue. We have found the experimental evidence to support this intuition in an eBay like simulation environment [21].

Resnick and Zeckhauser [22] study eBays reputation system and find that the reputation ratings are almost always positive. They conclude though reputation profiles are predictive of future performance, the profiles cannot be used as the best predictor available. Dellarocas [23] finds that eBay-like mechanisms can induce high average levels of cooperation that remain stable over time. The theoretical outcomes predicted by his paper are consistent with empirical observations and offer new, theory-backed, explanations to poorly understood phenomena such as the remarkably low fraction of negative feedback on eBay. Finally, it provides concrete suggestions on how eBay's current mechanism can be improved.

$\mathrm{Ba}$ et al. [15] propose to reduce online fraud through the use of reputation mechanism maintained by a trusted third party. According to their proposition a trusted third party not only issues a certificate but also maintains reputations associated with the certificate holder. They define a trusted third party system stage game to formalize the online transaction process with aid of trusted third parties and propose a symmetric sequential equilibrium strategy.

\section{Conclusions and scope for the future work}

In this paper we briefly discuss different kind of cheating possible in online auctions. We use theoretical models as well as a simulation experiments to study the impact of cheating in online auctions. Our cheating environments consist of shill bidding, bid shading and false bidding in English, first-price and second-price auction, respectively. We propose a framework that uses bidder's expected gain and seller's revenue loss to compare three important types of auctions.

We theoretically evaluate the bidder's expected utility and the sellers expected revenue loss under different probability of cheating for three different distributions of reservation values - uniform distribution, exponential distribution and some arbitrary polynomial distribution. The results are invariant of the underlaying distribution. Therefore, in the simulation experiments consider uniform distribution only. In each experiment the two types of bidders - ordinary bidders and the bidders with equilibrium bidding strategy and cheaters compete with each other. The English auction provides highest average expected utility to the bidders. Hence it can be said the English auction performs better from bidder's point of view.

Surprisingly the second-price auction in spite of its rarity is found to be most preferable type of auction from seller's point of view. Since our model is static in nature, the assumption of decreasing profit in second-price auction in dynamic models [12,9], can be used to explain that a cheating second-price will perform worse than that of the firstprice auction as time progresses. We find through the experiments that the revenue loss in English auction is less than the first-price auction. Therefore, English auction emerges as the most preferable mechanism for honest seller's point of view. Both theoretical and experimental results confirm the equilibrium bidding strategies indeed increase the bidders' expected utility. Therefore adoption of rational bidding strategies can combat cheating.

The present work can be extended in many ways. The result of multiple bidding can be studied in an environment where bid withdrawal is possible. A multistage gaming model can be used to see the effect of bid withdrawal at certain stage. While the purpose of shill bidding is to increase the seller's revenue, the multiple bidding is for decreasing the revenue. It will be interesting to observe the effect when both types of cheatings exist. Our model assumes that the shill never wins the auction. But in real-life sometimes the shills win. This model can be extended to accommodate this situation. The auction process over the internet involves three parties- the buyer (bidder), the seller and the site that hosts the auctions. Much work has been done to see the reputation effect of sellers. We plan to investigate the impact of reputation on the auction sites. Automated bidding agents can be developed that uses the bidding strategy discussed in the paper to counteract cheating. 


\section{References}

[1] Internet Fraud Complaint Center, Fraud Statistics, http:// www1.ifccfbi.gov/strategy/statistics.asp.

[2] Internet Fraud Complaint Center, Auction Fraud, http://wwwl.ifccfbi.gov/strategy/AuctionFraudReport.pdf.

[3] Ecommerce Times, Auction Fraud, http://www.ecommercetimes.com/perl/story/6590.html.

[4] Harry's Survey, http://www.harrispollonline.com.

[5] B. Bhargava, M. Jenamani, Y. Zhong, Understanding the impact of shill bidding in online English auctions, Technical Report CSD-TR 03-036, Department of Computer Science, Purdue University, 2003.

[6] K. Chui, R. Zwick, Auction on the Internet - A Preliminary Study. Available from: $<$ http://home.ust.hk/ mkzwick/papers/auction.pdf $>$.

[7] R. Porter, Y. Shoham, On cheating in sealed-bid auctions, in: Proceedings of the ACM Conference on Electronic Commerce 2003, pp. 76-84.

[8] W. Vickrey, Counter speculations auctions and competitive sealedbid tenders, Journal of Finance 41 (1961) 8-37.

[9] M.H. Rothkopf, T.J. Teisberg, E.P. Kahn, Why are Vickrey auctions rare? Journal of Political Economy 98 (1990) 94-109.

[10] J. Riley, W. Samuelson, Optimal auctions, American Economic Review 71 (3) (1981) 381-392.

[11] P. Klemperer, Auction theory: a guide to the literature, Journal of Economic Surveys 13 (3) (1999) 227-286.

[12] M. Rothkopf, R. Harstad, Two models of bid-taker cheating in vickrey auctions, The Journal of Business 68 (2) (1995) 257-267.

[13] D. Graham, R. Marshall, Collusive bidder behavior at single-object second-price and english auctions, Journal of Political Economy 95 (1987) 579-599.

[14] M. Yokoo, Y. Sakurai, S. Matsubara, The effect of false-name bids in combinatorial auctions: new fraud in internet auctions, Games and Economic Behavior (in press).
[15] S. Ba, A.B. Whinston, H. Zhang, Building trust in online auction markets through an economic incentive mechanism, Decision Support Systems 35 (2003) 273-286.

[16] R.J. Kauffman, C.A. Wood, Running up the bid: detecting, predicting, and preventing reserve price shilling in online auctions, working paper, Carlson School of Management, University of Minnesota, 2003. Available from: $<$ http://misrc.umn.edu/workingpapers/fullpapers/2003/0304_022003.pdf>.

[17] W. Wang, Z. Hidvegi, A.B. Whinston, Shill bidding in multi-round online auctions system sciences, 2002. HICSS, in: Proceedings of the 35th Annual Hawaii International Conference on, 7-10 January 2002.

[18] A.E. Roth, A. Ockenfels, 2002, Late-minute bidding and the rules for ending second-price auctions: evidence from eBay and Amazon on the Internet, American Economic Review 92 (4) (2002) 1093-1103.

[19] A. Likhodedov, T. Sandholm, Mechanism for optimally trading off revenue and efficiency in multi-unit auctions, in: Proceedings of the ACM Conference on Electronic Commerce, 2004.

[20] S.S. Fatima, M. Wooldridge, N. Jennings, Revenue maximising agendas for sequential english auctions, in: AAMAS'04, July 19-23, 2004, New York.

[21] B. Bhargava, M. Jenamani, Y. Zhong, 2005, Counteracting shill bidding in online English auction, International Journal of Cooperative Information Systems 14 (2-3) (2005).

[22] Paul Resnick, Richard Zeckhauser, 2002, Trust among strangers in internet transactions: empirical analysis of eBay's reputation system, in: Michael R. Baye (Ed.), The Economics of the Internet and ECommerce, Advances in Applied Microeconomics, vol. 11, Amsterdam, Elsevier Science, 2002.

[23] C. Dellarocas, Efficiency and Robustness of eBay-like Online Reputation Mechanisms in Environments with Moral Hazard, Massachusetts Institute of Technology, 2003.

[24] C.E.H. Chua, J. Wareham, Fighting Internet auction fraud: an assessment and proposal, IEEE Computer, October 2004. 